Brief Report

\title{
Assessing the Role of Emotional Associations in Mediating Crossmodal Correspondences between Classical Music and Red Wine
}

\author{
Qian (Janice) Wang * and Charles Spence \\ Crossmodal Research Laboratory, Oxford University, South Parks Road, Oxford OX1 3UD, UK; \\ charles.spence@psy.ox.ac.uk \\ * Correspondence: qian.wang@psy.ox.ac.uk; Tel.: +44-1865-271307
}

Academic Editor: Robert J. Harrington

Received: 13 November 2016; Accepted: 19 December 2016; Published: 1 January 2017

\begin{abstract}
Several recent studies have demonstrated that people intuitively make consistent matches between classical music and specific wines. It is not clear, however, what governs such crossmodal mappings. Here, we assess the role of emotion-specifically different dimensional aspects of valence, arousal, and dominance-in mediating such mappings. Participants matched three different red wines to three different pieces of classical music. Subsequently, they made emotion ratings separately for each wine and each musical selection. The results revealed that certain wine-music pairings were rated as being significantly better matches than others. More importantly, there was evidence that the participants' dominance and arousal ratings for the wines and the music predicted their matching rating for each wine-music pairing. These results therefore support the view that wine-music associations are not arbitrary but can be explained, at least in part, by common emotional associations.
\end{abstract}

Keywords: crossmodal correspondences; emotion mediation; wine; music; wine pairing

\section{Introduction}

The quest to find the perfect music to match with a wine has been taken up by writers (Johnson, 2005 [1]; http://wineandmusic.com/), wine makers (http://www.postmodernwinemaking.com/ wine-and-music), sommeliers (Sherman 2011 [2]), and marketers (notably by the luxury Champagne House Krug, https:/ /www.krug.com/krug-lovers/music-experience). In fact, it has been suggested that in the future, Michelin-starred restaurants might even provide music playlists to go with their wine lists (Cramb, 2008 [3]; Spence, 2011 [4]). In parallel, recent studies have demonstrated that people do indeed consistently match certain wines with specific pieces of music under conditions of forced choice (Spence et al., 2013 [5]; Wang \& Spence, 2015 [6]; see Spence \& Wang, 2015 [7], for a review). For instance, Spence et al. [5] reported that their participants found that Domaine Didier Dagueneau Pouilly Fumé matched significantly better with Mozart's Flute Quartet in D major-Movement 1 than with Tchaikovsky's String Quartet No 1-Movement 2; but the exact opposite result was observed for a glass of Chateau Margaux. Furthermore, in a subsequent experiment, tasting the wines while listening to matching music resulted in a small but significant increase in wine enjoyment as compared to tasting the same wines in silence.

What remains unclear, though, is the basis on which such wine-music correspondences are made by people. According to Spence (2011) [8], crossmodal correspondences can have structural, innate, statistical, or semantic origins. Furthermore, recent studies have demonstrated that common emotion evaluations can also help to explain certain crossmodal correspondences, such as, for example, colour-sound (Palmer et al., 2013 [9]), colour-odour (Schifferstein \& Tanudjaja, 2004 [10]), sound-odour (Levitan et al., 2015 [11]), shape-taste (Velasco et al., 2015 [12]), and even sound-taste correspondences 
(Wang et al., 2015 [13], 2016 [14]). The fact that both sound-taste and sound-odour correspondences can be mediated by emotion led us to hypothesise that the way in which people match music to wines might also be influenced by their shared emotional associations.

In order to measure these emotional associations, we used a version of the semantic differential scale. In fact, emotional associations can be viewed within the framework of the semantic differential technique where scales of bipolar adjectives are designed to measure people's attitudes-including emotions-towards a particular concept (Osgood et al., 1957 [15]). Semantic differential scales have, for instance, been shown to be a useful way of representing people's mental representations of odours (Dalton et al., 2008 [16]) and music (Watt \& Quinn, 2007 [17]). A pilot study $(N=25)$ using the same wines and music selection as the present study and 13 pairs of forced-choice bipolar adjectives ${ }^{1}$ revealed that participants did indeed consistently assign music pieces and wines to particular adjectives. In addition, there were significant correlations between how well participants rated a particular wine-music match and how consistently they rated the specific wine and music piece in terms of the adjective pairs weak/powerful $(r=0.87, p=0.002)$, male/female $(r=0.82, p=0.007)$, sad $/$ joyful $(r=0.73, p=0.025)$, and heavy/light $(r=0.86, p=0.003)$. Given such results, we proceeded to investigate whether the more specific shared emotion associations between wine-music pairs could mediate people's evaluation of wine-music correspondences.

\section{Methods}

\subsection{Participants}

Twenty-one participants ( 10 women, 11 men) between 22 and 63 years of age $(\mathrm{M}=32.7, \mathrm{SD}=10.2)$ took part in the study. The participants gave their informed consent, and reported no hearing impairments. The participants were recruited from the Oxford Blind Tasting Society and the Oxford Symposium on Food and Cookery. The experiment was approved by the Central University Research Ethics Committee of Oxford University (MSD-IDREC-C1-2014-205).

\subsection{Auditory Stimuli}

Three pieces of classical music were chosen for the study that varied in tempo, mode, and instrumentation. Sophia Giustani Dussek's Harp Sonata in C Minor is fast (130 BPM-beats per minute) and is in major mode. Sergei Rachmaninoff's Romance is a duet for cello and piano at a slow tempo (55 BPM) and minor tonality. Carl Off's Carmina Burana: Fortuna Imperatrix Mundi for male choir and orchestra has a medium tempo (112 BPM) and is in minor mode. All three pieces of music have been used in various demonstrations and talks related to sound-taste interactions. The Carmina Burana piece has frequently been used in wine-music demonstrations and would appear (anecdotally) to be a good match for bold, high-alcohol red wines.

\subsection{Wines}

Three red wines were chosen for the study that varied in body, acidity, and tannin levels. Only red wines were selected to avoid participants making wine-music matches based simply on the wine's colour (i.e., red vs. white), and to avoid temperature differences involved in chilling white wine. Domaine Pellé Menetou-Salon Morogues Pinot Noir 2014 has a light body, soft tannins, and high acidity. The Society's Blind Spot 2014 Grenache Shiraz Mataro (GSM) blend from McLaren Vale has full body, soft tannins, and low acidity. Scacciadiavoli Montefalco Rosso 2012 has full body, pronounced tannins, and high acidity. None of the wines have been used in previous studies, but wines from similar grape varieties or regions have been used in music-wine talks and demonstrations. For instance,

1 The adjective pairs were female/male, good/evil, powerful/weak, gentle/violent, joyful/sad, delicate/coarse, heavy/light, smooth/prickly, day/night, nervous/calm, pleased/angry, opulent/restrained, and hard/soft. 
Sagratino-based wines from Montefalco have been used to showcase tannins in wines [18], while a Pinot Noir wine from New Zealand was used by artist Jo Burzynska to showcase the influence of music on fruitiness and tannins.

Participants were served $30 \mathrm{~mL}$ samples of each wine, and each wine was tasted a total of four times over the course of the study.

\subsection{Dimensions}

Four dimensions were used to rate each wine and each music selection: preference (dislike-like), valence (sad-happy), arousal (calm-exciting), and dominance (weak-powerful). We used semantic differential scales with ratings from 0 to 10, and descriptors of each dimension were labeled at the ends of each scale. The dimensions of valence, arousal, and dominance were chosen to reflect the constructionist theory of emotions, following the well-established three-dimensional valence-arousal-dominance (VAD) model (Mehrabian 1991 [19], 1995 [20]; see Wyczesany \& Ligeza, 2015 [21], for EEG-based support).

\subsection{Procedure}

The experiment was conducted with participants sitting in a dimly-lit, sound-proof experiment room, in front of a computer monitor, with a keyboard, mouse, and headphones. There were also three glasses of wine, a cup of water, and a spittoon on the table. The experiment was programmed on the Qualtrics online survey platform.

Before the actual study began, the participants specified their gender, age, and self-rated wine expertise (amateur-no wine tasting experience, intermediate-less than two years of wine tasting experience, or expert-more than two years of wine tasting experience or working in the wine trade).

There were three blocks of trials. In the first block, each music selection was played once, over headphones, while the participants were instructed to taste all three wines in random order. Next, the participants assigned each wine a score from 0 to 10 depending on how well they thought that it matched the music (with $0=$ not at all, $10=$ a perfect match). The participants were instructed to rinse their mouths with water in between wines. During the second block, the participants tasted each wine again without music, in random order. After tasting each wine, they rated how much they liked the wine on a scale of 0 to 10 and how they would associate the wine with emotions on a $0-10$ scale of sad-happy $(0=$ sad, $10=$ happy $)$, calm-exciting $(0=$ calm, $10=$ exciting $)$, and weak-powerful $(0=$ weak, $10=$ powerful). Once again, the participants rinsed their mouths out with water in-between tasting. Finally, in the last block, the participants listened to all of the musical selections in a random order, and made the same liking, sad-happy, calm-exciting, and weak-powerful judgements. The study lasted for approximately $20 \mathrm{~min}$.

\section{Data Analysis}

Statistical software SPSS 23.0 (SPSS Inc., Chicago, USA) for Mac was used to analyse the results. A repeated-measured analysis of variance (RM-ANOVA) was conducted on participants' wine-music match ratings with music (3) and wine type (3) as factors. All reported $p$-values in post-hoc comparison tests have been Bonferroni corrected.

Since we collected emotion data relating to both wines and musical selections, we calculated the correlation between the emotion ratings of music and the emotion ratings of the wines best matched with each piece of music (see Results section for more detail, and see Palmer et al., 2013 [9], for an example of the same method).

\section{Results}

The mean values of participants' matching ratings between the wine selections and music selections are shown in Figure 1. 


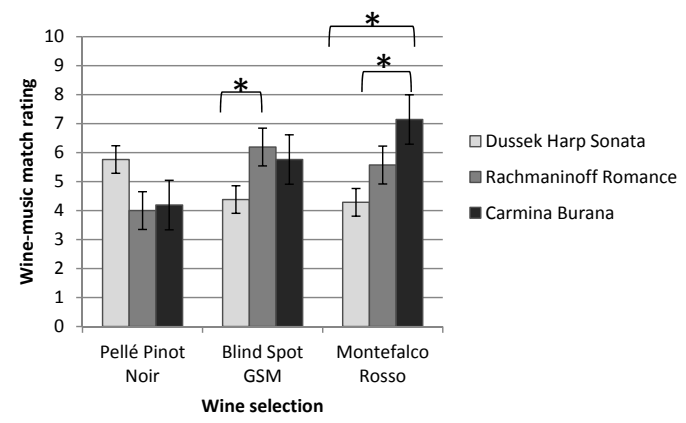

Figure 1. Mean wine-music match scores for all wine-music combinations, on a scale of 0 (does not match at all) to 10 (very good match). The error bars represent the standard error of means. * represents statistical significance at $p=0.05$.

An RM-ANOVA with wine type (Pellé Pinot Noir, Blind Spot GSM, and Montefalco Rosso) and music type (Dussek's Harp Sonata, Rachmaninoff's Romance, and Carmina Burana) as factors was conducted on participants' wine-music match ratings. Significant main effects of wine type $\left(F(2,40)=3.57, p=0.038, \eta^{2}=0.15\right)$ and of music type $\left(F(2,40)=4.48, p=0.018, \eta^{2}=0.18\right)$ were obtained. Pairwise comparisons revealed that, in general, the Dussek's Harp Sonata was a significantly poorer match for the wines than either the Rachmaninoff's Romance $(p=0.033)$ or Carmina Burana $(p=0.071)$. There was also a trend whereby Montefalco Rosso was a better match for all music selections as compared to the Pellé Pinot Noir.

Most importantly, we observed a significant interaction between music and wine $(F(4,80)=4.49$, $p=0.003, \eta^{2}=0.18$ ). Pairwise comparisons revealed that for the Blind Spot GSM, Rachmaninoff's Romance was a significantly better match than Dussek's Harp Sonata $(p=0.05)$; and for the Montefalco Rosso, the Carmina Burana selection was a significantly better match than both Dussek's Harp Sonata $(p=0.002)$ and Rachmaninoff's Romance $(p=0.036)$.

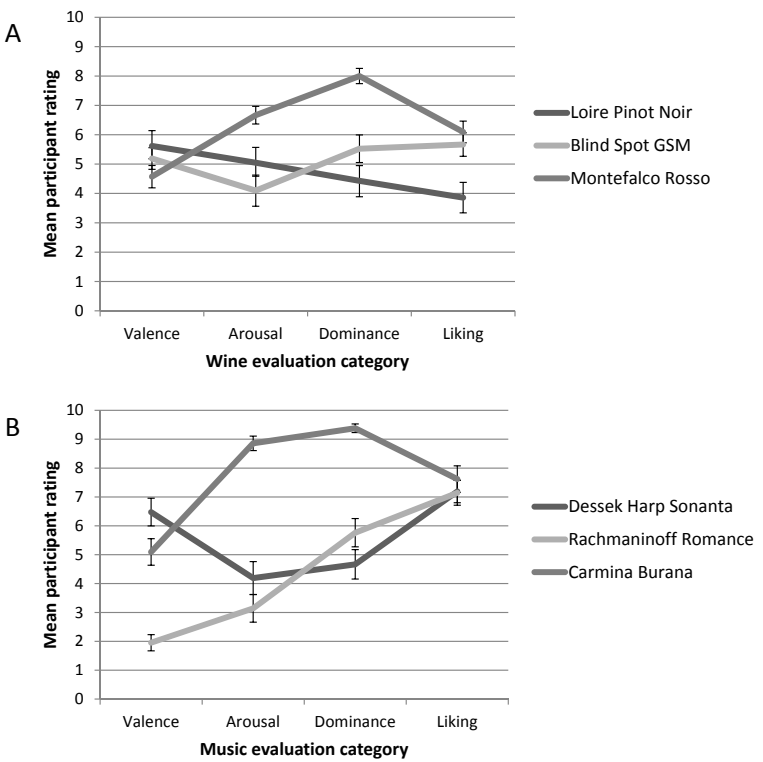

Figure 2. Mean emotion ratings of the wines (A) and music (B), each on a scale of $0-10$, for valence $(0=$ sad, $10=$ happy $)$, arousal $(0=$ calm, $10=$ exciting $)$, and dominance $(0=$ weak, $10=$ powerful $)$. Liking for the wine or music was also evaluated $(0=$ hate it, $10=$ love it). The error bars represent the standard error of the means.

The participants' emotion ratings for the various wines and music selections are shown in Figure 2. A RM-MANOVA with wine type as the within-participant factor and ratings of valence, 
arousal, dominance, and liking revealed a significant effect of wine type $(F(8,13)=5.06, p=0.005)$. Further univariate ANOVAs revealed that there were significant differences in arousal $(F(2,40)=7.96$, $p=0.001)$, dominance $(F(2,40)=17.35, p<0.0005)$, and liking $(F(2,40)=7.41, p=0.002)$ ratings, but not for valence ratings $(F(2,40)=5.83, p=0.25)$. The Montefalco Rosso was rated as significantly higher in arousal and dominance than the Pellé Pinot Noir ( $\left.p_{\text {arousal }}=0.02, p_{\text {dominance }}<0.0005\right)$ and Blind Spot GSM ( $\left.p_{\text {arousal }}=0.001, p_{\text {dominance }}<0.0005\right)$. Furthermore, the Pellé Pinot Noir was liked less than the Montefalco Rosso $(p=0.007)$ and the Blind Spot GSM $(p=0.043)$.

Similarly, a RM-MANOVA with music type as the within-participant factor and ratings of valence, arousal, dominance, and liking revealed a significant effect of music type $(F(8,13)=26.02, p<0.0005)$. Further univariate ANOVAs showed that there were significant differences in valence $(F(2,40)=27.16$, $p<0.0005)$, arousal $(F(2,40)=49.01, p<0.0005)$, and dominance $(F(2,40)=42.72, p<0.0005)$ ratings, but not for liking ratings $(F(2,40)=0.41, p=0.67)$. Rachmaninoff's Romance was rated as significantly lower in valence than Dussek's Harp Sonata or Carmina Burana, and Carmina Burana was rated to be significantly higher in arousal and dominance than Dussek's Harp Sonata or Rachmaninoff's Romance ( $p<0.0005$ for all comparisons).

To analyse the role of emotion in mediating the matching between music and wine, the correlations between participants' wine-music match scores, and how similar their emotion ratings were for the particular combination of music and wine, were calculated. For each of the $3 \times 3=9$ possible music-wine combinations, we calculated a set of soundtrack-wine similarity ratings ( $\left(\mathrm{S}_{\text {music,wine,emotion }}\right)$, equal to 10 minus the absolute difference between each emotion dimension rating for the given piece of music and wine. In other words, the more similar the rating for a piece of music and a particular wine, the higher the SR score would be (out of 10). For each music-wine combination, we then calculated the correlation between the SR score and the participants' wine-music match response for each emotion dimension. The idea being that if an emotional dimension, say valence, influences the degree of correspondence between a particular wine $W$ and a piece of music $M$, then we would expect a positive correlation between the $\mathrm{SR}_{M, W \text {,valence }}$ and the $M-W$ matching score.

We found Pearson correlation coefficients of $0.01(p=0.89)$ for valence, $-0.02(p=0.76)$ for arousal, $0.28(p<0.0005)$ for dominance, and $0.05(p=0.52)$ for liking. Since some similarity ratings are collinear (see Table 1), we then computed partial correlations of each matching score-emotion similarity rating pair, while controlling for all other emotion ratings (see Table 2). The results suggest that the emotional dimensions of dominance (the spectrum between weak-powerful) as well as arousal (the spectrum between calm-exciting) mediate music-wine matching to some degree.

Table 1. Pearson correlation coefficients $(N=189)$ amongst participants' emotion similarity ratings. * indicates significance at 0.05 level, ${ }^{* *}$ indicates significance at 0.01 level.

\begin{tabular}{ccccc}
\hline & $\begin{array}{c}\text { Valence } \\
\text { Similarity }\end{array}$ & $\begin{array}{c}\text { Arousal } \\
\text { Similarity }\end{array}$ & $\begin{array}{c}\text { Dominance } \\
\text { Similarity }\end{array}$ & Liking Similarity \\
\hline Valence similarity & 1 & 0.076 & 0.007 & $0.144^{*}$ \\
Arousal similarity & & 1 & $0.377^{* *}$ & 0.034 \\
Dominance similarity & & & 1 & 0.074 \\
Liking similarity & & & & 1 \\
\hline
\end{tabular}

Table 2. Partial correlation coefficients $(N=189)$ between participants' wine-music matching scores and emotion similarity ratings. ${ }^{*}$ indicates significance at the 0.05 level, ${ }^{* *}$ indicates significance at the 0.01 level.

\begin{tabular}{ccc}
\hline Emotion Dimension & Partial Correlation Coefficient & Controlling for \\
\hline Valence & 0.016 & Arousal, dominance, liking \\
Arousal & $-0.144^{*}$ & Valence, dominance, liking \\
Dominance & $0.308^{* *}$ & Valence, arousal, liking \\
Liking & 0.026 & Valence, arousal, dominance \\
\hline
\end{tabular}


Out of 21 participants, 4 rated their wine tasting expertise at beginner level (no wine tasting experience), 8 at intermediate level (less than two years of wine tasting experience), and 9 at expert level (more than two years of wine tasting experience or working in the wine trade). To examine the role of wine expertise, the participants were binned into two groups: those at expert level and those at beginner and intermediate levels. Regarding the wine-music matching choices, a similar RM-ANOVA as above, with group type added as another between-participant factor, revealed no significant interaction effects between music type, wine type, and level of expertise $(F(4,76)=1.21$, $p=0.31$ ). Partial correlations between wine-music matching scores and emotion similarity ratings showed that both groups displayed significant positive correlations for dominance ratings, but only the group with more wine expertise showed a significant negative correlation for arousal ratings (see Table 3). In other words, those with wine expertise were using contrasting calm/excitement ratings when it came to wine-music matching.

Table 3. Partial correlation coefficients $(N=189)$ between participants' wine-music matching scores and emotion similarity ratings for more and less experienced wine tasters. ${ }^{*}$ indicates significance at the 0.05 level, ${ }^{* *}$ indicates significance at the 0.01 level.

\begin{tabular}{cccc}
\hline Emotion Dimension & Controlling for & $\begin{array}{c}\text { Partial } \boldsymbol{r} \\
\text { (Less Experienced Tasters) }\end{array}$ & $\begin{array}{c}\text { Partial } \boldsymbol{r} \\
\text { (More Experienced Tasters) }\end{array}$ \\
\hline Valence & Arousal, dominance, liking & -0.068 & 0.145 \\
Arousal & Valence, dominance, liking & -0.066 & $-0.238^{*}$ \\
Dominance & Valence, arousal, liking & $0.224^{*}$ & $0.425^{* *}$ \\
Liking & Valence, arousal, dominance & 0.063 & -0.034 \\
\hline
\end{tabular}

\section{Discussion}

The results of the present study reveal that certain wine-music pairings were rated as a better match than others, thus reaffirming prior findings that people can make consistent matches between certain wines and music selections (Spence et al., 2013 [5]; Spence \& Wang, 2015 [7]; Wang \& Spence, 2015 [6]). Interestingly, participants' level of wine tasting expertise did not significantly influence the way in which they made the wine-music matches, thus suggesting that these correspondences are not skills-dependent. Overall, our results were consistent with the emotional mediation hypothesis, specifically for the emotion dimensions of dominance and arousal. The current study showed that, given a range of red wines and classical music, people are more likely to rate a specific wine and music selection as matching well if both are associated with similar levels of weakness/power but dissimilar levels of calm/excitement.

It is worth noting that, contrary to what we had planned, the wines and music did not differ significantly on all dimensions. As the results showed, the wines did not differ significantly in valence ratings, just as the music pieces did not differ significantly in liking ratings. Therefore, participants might not have been able to distinguish the wines or music as clearly as we would have liked. Moreover, the range of emotional ratings of the wines in the current study might have been limited by the use of only red wines, just as the range of musical emotions might have been limited by the use of only classical music. Therefore it should be acknowledged that the inclusion of a wider spectrum of wines and music in future research might uncover a greater role for valence or preference.

One possible explanation for why dominance particularly stands out in the correlation analysis is that, compared to the happy/sad or calm/exciting adjective pairs, weak/strong is already used in a wine-tasting context. Therefore, participants might find it easier to evaluate wines on a weak/strong scale and rely on it more when making their music-wine matches. On the other hand, if it were only a matter of familiarity with the adjectives used in the rating scales, then one could argue that we should have found a significant correlation for the preference/liking ratings as well.

Another interesting takeaway from the present study is the small but significant negative correlation between participants' wine-music match scores and arousal similarity ratings. In other words, participants were more apt to match wines and music with contrasting arousal ratings, so that a 
wine which evokes a sense of calm might be better matched to an exciting piece of music. It is possible that participants were reflecting learned food-pairing principles, where a stimulating food (such as spicy curry) might be balanced with a calming food (such as yogurt) to complement one another. Of course, such conclusions need to be taken with a grain of salt since the negative correlation is small, and after all, the music with the highest arousal rating was best matched to the wine with the highest arousal rating.

Another notable limitation of the current study is the relatively small sample size $(N=21)$. It seems unlikely that true randomness in the order of the participants' wine-music conditions would have been achieved; therefore, the results could have been confounded by order of trial effects. For future testing, a Williams design Latin square structure would be more appropriate. Furthermore, even though the room was dimly-lit, participants could still perhaps have relied on subtle colour differences between the three wines to make their judgments. After all, while the Blind Spot GSM and Montefalco Rosso were both very dark in colour, the Loire Pinot Noir was a distinctly paler ruby. That said, the results showed significant music matching differences between the Blind Spot GSM and Montefalco Rosso, even though they had very similar colours.

In summary, the present study found limited evidence that, given a selection of red wines and classical music, music-wine matches were likely to be mediated by emotion. This finding has clear implications for those designing bespoke wine-music matches, whether in an artistic or retail setting. Perhaps the winemaker Clark Smith put his finger on something important when he once said that:

"Red wines need either minor key or they need music that has negative emotion. They don't like happy music ... Cabernets like angry music." (Gray, 2007 [22]).

Acknowledgments: CS would like to thank the AHRC grant entitled 'Rethinking the senses' (AH/L007053/1) for supporting this research.

Author Contributions: Q.J.W. and C.S. designed the study. Q.J.W. collected the data and performed data analysis. Q.J.W. and C.S. participated in manuscript preparation. All authors read and approved the final manuscript.

Conflicts of Interest: The authors declare no conflicts of interest.

\section{References}

1. Johnson, H. Wine: A Life Uncorked; Weidenfeld \& Nicolson: London, UK, 2005.

2. Sherman, A. Perfect Pairings: Programming Wine with Music. NPR Music. 22 November 2011. Available online: http://www.npr.org/sections/deceptivecadence/2011/11/21/142590064/perfectpairings-programming-wine-with-music (accessed on 22 December 2016).

3. Cramb, A. Why Wine Tastes Better with Music. The Telegraph, 13 May 2008. Available online: http://www.telegraph.co.uk/news/uknews/1952381/Why-wine-tastes-better-with-music.html (accessed on 22 December 2016).

4. Spence, C. Wine and music. World Fine Wine 2011, 31, 96-104.

5. Spence, C.; Richards, L.; Kjellin, E.; Huhnt, A.M.; Daskal, V.; Scheybeler, A.; Velasco, C.; Deroy, O. Looking for crossmodal correspondences between classical music \& fine wine. Flavour 2013, 2, 29.

6. Wang, Q.; Spence, C. Assessing the effect of musical congruency on wine tasting in a live performance setting. i-Perception 2015, 6, 1-13.

7. Spence, C.; Wang, Q.J. Wine \& music (I): On the crossmodal matching of wine \& music. Flavour 2015, 4, 34.

8. Spence, C. Crossmodal correspondences: A tutorial review. Atten. Percept. Psychophys. 2011, 73, 971-995. [CrossRef] [PubMed]

9. Palmer, S.E.; Schloss, K.B.; Xu, Z.; Prado-León, L.R. Music-color associations are mediated by emotion. Proc. Natl. Acad. Sci. USA 2013, 110, 8836-8841. [CrossRef] [PubMed]

10. Schifferstein, H.N.J.; Tanudjaja, I. Visualizing fragrances through colors: The mediating role of emotions. Perception 2004, 33, 1249-1266. [CrossRef] [PubMed]

11. Levitan, C.A.; Charney, S.A.; Schloss, K.B.; Palmer, S.E. The smell of jazz: Crossmodal correspondences between music, odor, and emotion. In Proceedings of the 37th Annual Meeting of the Cognitive Science Society, Pasadena, CA, USA, 22-25 July 2015; pp. 1326-1331. 
12. Velasco, C.; Woods, A.; Deroy, O.; Spence, C. Hedonic mediation of the crossmodal correspondence between taste and shape. Food Qual. Preference 2015, 41, 151-158. [CrossRef]

13. Wang, Q.; Woods, A.; Spence, C. "What's your taste in music?" A comparison of the effectiveness of various soundscapes in evoking specific tastes. i-Perception 2015, 6, 3. [CrossRef] [PubMed]

14. Wang, Q.; Wang, S.; Spence, C. "Turn up the taste": Assessing the role of taste intensity and emotion in mediating crossmodal correspondences between basic tastes and pitch. Chem. Senses 2016, 41, 345-356. [CrossRef] [PubMed]

15. Osgood, C.E.; Suci, G.; Tannenbaum, P. The Measurement of Meaning; University of Illinois Press: Urbana, IL, USA, 1957.

16. Dalton, P.; Maute, C.; Oshida, A.; Hikichi, S.; Izumi, Y. The use of semantic differential scaling to define the multi-dimensional representation of odors. J. Sens. Stud. 2008, 23, 485-497. [CrossRef] [PubMed]

17. Watt, R.; Quinn, S. Some robust higher-level percepts for music. Perception 2007, 36, 1834-1848. [CrossRef] [PubMed]

18. Youssef, J. A Sensory Exploration of Wine Seminar. Available online: https://www.kitchen-theory.com/ seminar-networking-event-a-sensory-exploration-of-wine/ (accessed on 22 December 2016).

19. Mehrabian, A. Outline of a general emotion-based theory of temperament. In Explorations in Temperament: International Perspectives on Theory and Measurement; Strelau, J., Angleitner, A., Eds.; Plenum: New York, NY, USA, 1991; pp. 75-86.

20. Mehrabian, A. Framework for a comprehensive description and measurement of emotional states. Genet. Soc. Gen. Psychol. Monogr. 1995, 121, 339-361. [PubMed]

21. Wyczesany, M.; Ligeza, T.S. Towards a constructionist approach to emotions: Verification of the three-dimensional model of affect with EEG-independent component analysis. Exp. Brain Res. 2015, 233, 723-733. [CrossRef] [PubMed]

22. Gray, W.B. Music to Drink Wine by: Vintner Insists Music Can Change Wine's Flavors. San Francisco Chronicle, 11 November 2007. Available online: http://www.sfgate.com/wine/article/Music-to-drink-wineby-Vintner-insists-music-can-3235602.php on (accessed on 13 August 2015).

(C) 2017 by the authors; licensee MDPI, Basel, Switzerland. This article is an open access article distributed under the terms and conditions of the Creative Commons Attribution (CC-BY) license (http://creativecommons.org/licenses/by/4.0/). 